\title{
Utilization and Expenditures
}

\section{Impact of Pharmacy Benefit Design on Prescription Drug Utilization: A Fixed Effects Analysis of Plan Sponsor Data}

\author{
M. Christopher Roebuck and Joshua N. Liberman
}

Objective. To study the impact of various elements of pharmacy benefit design on both the absolute and relative utilization of generics, brands, retail pharmacy, and mail service. Data Source. Panel data on 1,074 plan sponsors covering 21.6 million individuals over 12 calendar quarters (2005-2007).

Study Design. A retrospective analysis of pharmacy claims.

Statistical Methods. To control for potential endogeneity, linear fixed effects models were estimated for each of six dependent variables: the generic utilization rate, the brand utilization rate, the generic dispensing rate (GDR), the retail pharmacy utilization rate, the mail service utilization rate, and the mail distribution rate.

Principal Findings. Most member cost-share variables were nonlinearly associated with changes in prescription drug utilization. Marginal effects were generally greater in magnitude for brand out-of-pocket costs than for generic out-of-pocket costs. Time dummies, as well as other pharmacy benefit design elements, also yielded significant results.

Conclusions. Prior estimates of the effect of member cost sharing on prescription drug utilization may be biased if complex benefit designs, mail service fulfillment, and unmeasured factors such as pharmaceutical pipelines are not accounted for. Commonly cited relative utilization metrics, such as GDR, may be misleading if not examined alongside absolute prescription drug utilization.

Key Words. Pharmacy benefit design, cost sharing, generic dispensing, mail service utilization

In 2007, approximately 3.81 billion prescriptions were dispensed in the United States (IMS Health 2008), and the associated pharmacy costs accounted for 10.1 percent of the nearly $\$ 2$ trillion in national health care expenditures (KFF/HRET 2007). Between 1994 and 2003, prescription drug expenditures increased in excess of 10 percent annually; and though moderating in recent years, they still rose by 8.6 percent from 2005 to 2006 (CMS 
2008). Insurers have responded with more complex pharmacy benefit designs to encourage their members through financial incentives to make lower cost decisions. Although many studies have investigated the impact of patient cost sharing on prescription drug utilization, few have accounted for the other elements of benefit design. Furthermore, pharmacy utilization trends related to demographics, brand and generic drug pipelines, and prescription delivery options have also been largely unstudied. Finally, the extant literature in this area has largely focused on absolute levels of prescription drug utilization, yet pharmacy benefit managers (PBMs) and their recommended plan designs are often evaluated using relative utilization measures such as the generic dispensing rate (GDR). This paper examines the relationship between pharmacy benefit design and prescription drug utilization, including both absolute and relative measures of generic, brand, retail, and mail use. Using a plan sponsorlevel panel dataset, the econometric analysis addresses the potential endogeneity of pharmacy benefit design by way of linear fixed effects modeling.

\section{BACKGROUND}

Health insurance spreads financial risk but also induces moral hazard (e.g., Cutler and Zeckhauser 2000; Phelps 2003). Insured individuals consume greater quantities of health care services than they would have in the absence of insurance because they face "prices" (as copayments/coinsurance) that are below full costs. Health plans, employers, governments, and other insurance plan sponsors rely on the incentives embedded in benefit designs to reduce this undesirable inefficiency. In the context of prescription drug insurance, the optimal policy would not only balance the gains from risk avoidance with the losses from moral hazard but would also take into account how changes in medication adherence (particularly for chronic conditions) might affect overall health services utilization and costs (Newhouse 2006; Ellis and Manning 2007). Although physicians prescribe the treatment regimen, they do not necessarily do so with drug cost or formulary placement in mind (Shrank et al. 2005). Consequently, it is the patient who must inquire about lower cost alternatives under his/her prevailing insurance and ultimately

Address correspondence to M. Christopher Roebuck, M.B.A., Director of Strategic Research, CVS Caremark, 11311 McCormick Road, Suite 230, Hunt Valley, MD 21031; e-mail: chris.roe buck@caremark.com. Joshua N. Liberman, Ph.D., Vice President of Strategic Research, is with CVS Caremark, Hunt Valley, MD. 
choose to fill the prescription as written, change to a less costly drug, use mail service fulfillment, or forego treatment.

\section{Elements of Pharmacy Benefit Design}

Incentivized formularies, the cornerstone of many prescription benefit structures, classify drugs into tiers based on safety, clinical effectiveness, acquisition cost, availability of comparable medications, and other criteria (Mullins, Palumbo, and Saba 2007). The amount paid by the patient for a medication increases with tier placement. Typically, generic drugs deemed therapeutically equivalent (identical in strength, concentration, and dosage form) to a brand drug are assigned to the first tier. Brand drugs, which are patent protected and manufactured by a single pharmaceutical company, are normally placed in higher tiers. In three-tier formularies, brand drugs are divided into second-tier (preferred) brands and third-tier (nonpreferred) brands, which often include brands with an available generic equivalent (i.e., multisource brands). In four-tier formularies, brand drugs may be further differentiated with higher member shares for lifestyle drugs or specialty medications such as biologics. As of 2007, approximately 75 percent of covered employees were enrolled in plans with three or more tiers, up from 27 percent in 2000 (KFF/ HRET 2007). In three-tier plans, copayments have increased from 2000 to 2007 with generic, preferred brand, and nonpreferred brand prescriptions growing on average $37.5,66.7$, and 48.3 percent to average copayments of $\$ 11, \$ 25$, and $\$ 43$ (KFF/HRET 2007). Among two-tier employer-sponsored plans, generic copayments averaged $\$ 7$ and brand copayments averaged $\$ 23$ in 2007, an increase of 42.9 and 64.3 percent since 2000 (KFF/HRET 2007).

In addition to cost sharing, prescription drug plans include other tools to motivate patient behavior. First, members may incur a dispense-as-written (DAW) financial penalty when a multisource brand prescription is demanded despite the availability of a generic equivalent. Two types of DAW penalties may be imposed: (1) a DAW penalty if the patient refuses the generic formulation and (2) a DAW penalty if either the patient or provider refuses the generic formulation. Another mechanism that is seeing increased use is the deductible, a fixed dollar amount that must first be paid by the member before insurance benefits pay out. In recent years, consumer-directed health plans have gained in popularity, and these benefit designs often combine high deductibles with health retirement/savings accounts. A third strategy employed to control prescription drug costs is to encourage plan participants to allow mail delivery of their medications for chronic conditions. This is most often 
accomplished by offering lower patient out-of-pocket (OOP) costs per medication day supplied or by limiting the number of refills allowed at retail pharmacies. Finally, a prescription plan might also contain a maximum allowable benefit (MAB), which places a cap on the amount covered by the payor. This is in contrast to a maximum out-of-pocket (MOOP), which limits the member's financial responsibility.

\section{Utilization Impacts of Pharmacy Beneft Design}

At least since the Rand Health Insurance Experiment (RHIE; Manning et al. 1987), researchers and policy makers have been concerned with the relationship between plan design and the demand for medical care. Of particular interest has been the impact of cost sharing on utilization. In the context of prescription drugs, Gemmill, Costa-Font, and McGuire (2007) provide an excellent literature review on the topic and derive a "corrected" price elasticity of demand estimate of -0.209 via a metaregression analysis. Other studies of pharmacy benefit design have consistently found higher patient cost shares and more formulary tiers to be associated with (1) greater use of lower cost drugs (Nair et al. 2003; Rector et al. 2003; Huskamp et al. 2007; Landon et al. 2007; Mager and Cox 2007), (2) lower overall utilization either in the form of treatment discontinuation or noninitiation (Motheral and Fairman 2001; Fairman, Motheral, and Henderson 2003; Huskamp et al. 2003; Nair et al. 2003; Goldman et al. 2004; Landsman et al. 2005; Brixner et al. 2007; Gilman and Kautter 2007, 2008; Chernew et al. 2008), (3) decreased plan sponsor expenditures (Motheral and Fairman 2001; Fairman, Motheral, and Henderson 2003; Brixner et al. 2007; Gilman and Kautter 2007, 2008; Landon et al. 2007), and (4) by definition, higher consumer costs per prescription.

Fewer studies have investigated the impact of incentivized formularies and cost sharing on relative utilization measures. The GDR, the proportion of all prescriptions filled as generic, is often used to evaluate PBMs and their recommended plan designs. Moreover, the Centers for Medicare and Medicaid Services (CMS) consider GDR a performance metric for Part D prescription drug plans (CMS 2006). Leibowitz, Manning, and Newhouse (1985) and more recently Motheral and Fairman (2001) reported no significant change in GDR following the implementation of an aggressive change in benefit design. In a cross-sectional study of 3,979 plan sponsors, Mager and Cox (2007) found three-tier formularies had GDRs that were on average 2 percentage points higher than two-tier structures. Landon et al. (2007) conducted a 2-year, pre-post study of formulary changes within a single, large 
health plan and noted that implementing a third tier or increasing member copayments was associated with a 1-4 percent decrease in nonformulary drug use, a comparable increase in both generic and preferred drug utilization, and an approximate doubling of mail service use. Moreover, Nair et al. (2003) showed that implementing a three-tier formulary resulted in a 5.6 percent increase in formulary compliance, but only a slight shift to generics. Findings from a more recent study by Gilman and Kautter (2007) were mixed. Analysis of a sample of 352,760 Medicare enrollees with employer-sponsored supplemental insurance suggested a 10 percent increase in copayment levels would be associated with a 1.3 percent reduction in gross drug spending, a 16.0 percent increase in member OOP costs, a 2.0 percent decline in overall utilization, and a decrease in GDR of 0.7 percent. However, a 10 percent increase in relative copayments, the brand-to-generic copayment differentials after adjusting for absolute copayments, would be associated with a 1.0 percent reduction in gross drug spending, a 4.1 percent increase in member OOP costs, a 1.0 percent decline in overall utilization, and an increase in GDR of 0.7 percent. The authors conclude that multitiered formularies provide incentives with conflicting effects, and that the specific formulary structure may have a major effect on access to prescription medications. In a related study, Gilman and Kautter (2008) found three-tier formularies had GDRs that were 4.3 percentage points higher than comparable one-tier plans. Like the majority of the studies reviewed, Gilman and Kautter $(2007,2008)$ did not control for the independent effects of mail service OOP costs, despite including mail service claims in the dependent variables for prescription utilization.

In 2007, approximately 6.9 percent of all prescriptions were delivered via mail (NACDS 2008). Because of purchasing, storage, and dispensing efficiencies, mail service pharmacies can deliver prescriptions at lower unit costs than retail. However, to offset shipping costs, mail service pharmacies typically dispense 90 days of maintenance medication supply for chronic conditions, rather than the 30 days of supply normally dispensed at retail pharmacies. Consequently, there are two competing financial incentives to use mail over retail: the consumer often pays significantly less per day of therapy, while paying substantially more in total for the 90-day prescription. The extant literature provides little examination of the impact of pharmacy benefit design on mail service utilization.

A final, important challenge of many studies on the impact of insurance on utilization is potential endogeneity. In the absence of a randomized-controlled trial like the RHIE, estimated effects of cost sharing and other elements of pharmacy benefit design on prescription drug utilization can only be interpreted as correlational and not causal. Indeed, unobserved characteristics 
related to both the explanatory variable of interest (e.g., generic copayment) and the modeled outcome (e.g., generic utilization) may lead to biased coefficient estimates. Cross-sectional studies are particularly limited in this regard (e.g., Goldman et al. 2004). On the other hand, cross-sectional time series data allow for the removal of the unobserved effect through time demeaning (i.e., "within" transformation; Wooldridge 2002, pp. 290-1). In addition to the contributions already discussed, the present study expands the literature significantly by employing linear fixed effects models to control for the potential endogeneity of pharmacy benefit design.

\section{METHODS}

\section{Data}

Pharmacy claims and eligibility data were extracted and aggregated at the plan level to create a panel dataset of PBM clients serviced by CVS Caremark during the period January 1, 2005 through December 31, 2007. All plans included in the sample had both retail pharmacy and mail delivery options, and had either a two-tier or three-tier formulary. All variables used in the analysis were calculated as means, weighted by the number of eligible participants within each client-quarter observation. The final sample included a total of 1,074 plan sponsors, which covered over 21.6 million individuals, and consisted of 1,002 employers and 72 health plans over 12 calendar quarters.

\section{Independent Variables}

Several independent variables were constructed for each client by quarter. Demographic characteristics included the percentage of members that were male, the proportion of covered individuals in each of five age groups (0-11, $12-18,19-39,40-64$, and 65+), and the geographic concentration within each of five region categories (West, Midwest, Northeast, South, and other/unknown). An indicator differentiating three-tier from two-tier plans was retained, as was a dichotomous flag to distinguish employers from health plan sponsors. Additionally, a vector of 11 quarterly time dummies was incorporated in all models to control for unobserved time-varying characteristics common to all clients (e.g., pharmaceutical pipeline).

Measures of patient OOP cost by tier were derived using either flat copayment amounts or, where applicable, by multiplying coinsurance rates times the average prescription drug cost. Thus, for two-tier plans, two continuous variables were created: the OOP cost for a generic prescription at 
retail and the OOP cost for a brand at retail. For three-tier clients, three variables were needed to distinguish preferred brands (second tier) from nonpreferred brands (third tier). Mail-order prescriptions usually include 90 days of medication supply as opposed to the 30 days commonly supplied by retail pharmacies. One would expect patients, when choosing between retail and mail fulfillment, to most consider relative mail-retail OOP costs. Setting aside other potential costs and benefits, mail service is cheaper for an individual when the OOP cost for a given prescription at mail is less than three times its OOP cost at retail. To control for this incentive/disincentive to use mail service, tier-specific mail-retail OOP cost ratios were derived by dividing mail OOP costs by retail OOP costs. Squared terms for both the absolute measures of retail OOP costs, as well as the relative measures of mail-retail OOP cost ratios, were also included in the ensuing models as suggested by results from Ramsey's (1969) RESET test for functional form. A vector of seven dichotomous covariates included in all models indicating the presence of other retail pharmacy benefit design characteristics were as follows: (1) retail coinsurance-whether the patient OOP cost variables were calculated using coinsurance rates via the method described previously, (2) mandatory mailwhether the plan required maintenance medications for chronic conditions be dispensed via mail service after the filling of one or two retail prescriptions, (3) retail deductible, (4) retail MAB, (5) retail MOOP, and (6 and 7) each of the two types of retail DAW penalty; all as defined previously.

\section{Dependent Variables}

Finally, the statistical analysis examined six outcomes: (1) the generic utilization rate-the number of generic prescription fills per eligible plan member per quarter (PMPQ), (2) the brand utilization rate-the number of brand prescription fills PMPQ (3) the GDR-the proportion of all prescriptions filled as generic, (4) the retail utilization rate-the number of prescriptions filled at retail pharmacies PMPQ, (5) the mail utilization rate-the number of prescriptions filled via mail service PMPQ, and (6) the mail distribution rate (MDR) - the proportion of all prescriptions that were delivered through mail service pharmacies. All six measures were calculated using 30-day supplyadjusted prescription counts (i.e., 1 mail $\mathrm{Rx}=3$ retail $\mathrm{Rxs}$ ).

\section{Econometric Analyses}

For each of the six dependent variables, the viability of using a random effects estimator was first explored and unanimously rejected $(p<.01)$ using the he- 
teroskedasticity-robust form of the Hausman (1978), Wu (1973) specification test suggested by Wooldridge (2002, pp. 290-1). Instead, linear fixed effects models with Driscoll and Kraay (1998) robust standard errors were estimated as described by Hoechle (2007). In addition to removing time invariant, unobserved plan sponsor characteristics that may potentially confound results, this technique produces a covariance matrix that is consistent in cases of heteroskedasticity across panels, within-panel serial correlation, as well as cross-sectional dependence. All of these issues emerged in the current analysis. Groupwise nonconstant variance was detected based upon the rejection of homoskedasticity $(p<.01)$ using a modified Wald test (Greene 2003, p. 598). Employing the test recommended by Wooldridge (2002, pp. 274-6) and Drukker (2003), the null hypothesis of no first-order autocorrelation was also rejected $(p<.01)$. Finally, cross-sectional independence in the error term was tested and not rejected $(p>.10)$ in most, but not all models using Pesaran's (2004) technique. All analyses were conducted using Stata/MP 10.1 (StataCorp 2008).

\section{RESULTS}

Table 1 provides descriptive statistics for all variables used in the analysis. The sample of prescription drug plans was predominantly from the Midwest (33 percent) and South (32 percent), was overwhelmingly employer sponsored (93 versus 7 percent health plans), and largely had three-tier benefit designs (69 versus 31 percent two tier). Although 50 percent of two-tier plans used retail coinsurance rates to determine member retail OOP costs, 80 percent of threetier clients had flat retail copayments. Among three-tier clients, the average retail OOP costs for generic, preferred brand, and nonpreferred brand prescriptions at retail were $\$ 8.79, \$ 22.78$, and $\$ 36.75$, respectively. Two-tier plans had lower mean retail generic OOP costs $(\$ 7.25)$ and only slightly higher retail brand OOP costs $(\$ 23.33)$ than three-tier retail preferred brand OOP costs. Average mail-retail OOP cost ratios ranged from 1.78 to 2.12 , and mail service was mandatory for maintenance medications in 17 percent of plans. Finally, 33 percent of plans had a patient type retail DAW penalty; however, retail $\mathrm{MAB}$, retail MOOP, and retail deductible were far less common pharmacy benefit design elements.

Also presented in Table 1 are mean values for the six prescription utilization measures. Plan members consumed 3.54 prescriptions per quarter, 52 percent of which were generic and 65 percent dispensed at retail pharmacies. Throughout the study period, GDR steadily rose from 47 to 58 percent as a 
Table 1: Sample Statistics $(N=1,074)$

\begin{tabular}{|c|c|c|}
\hline Variable & Mean & $S D$ \\
\hline \multicolumn{3}{|l|}{ Prescription drug utilization measures* } \\
\hline Number of generic rxs PMPQ & 1.816 & 1.105 \\
\hline Number of brand rxs PMPQ & 1.719 & 1.010 \\
\hline Generic dispensing rate (GDR) & 0.518 & 0.060 \\
\hline Number of retail rxs PMPQ & 2.204 & 1.525 \\
\hline Number of mail rxs PMPQ & 1.331 & 1.261 \\
\hline Mail distribution date (MDR) & 0.348 & 0.201 \\
\hline \multicolumn{3}{|l|}{ Plan sponsor characteristics } \\
\hline Ages $0-11$ & 0.148 & 0.054 \\
\hline Ages $12-18$ & 0.108 & 0.036 \\
\hline Ages 19-39 & 0.271 & 0.094 \\
\hline Ages 40-64 & 0.377 & 0.097 \\
\hline Age $65+$ & 0.083 & 0.144 \\
\hline Male & 0.492 & 0.073 \\
\hline West region & 0.116 & 0.243 \\
\hline Northeast region & 0.132 & 0.252 \\
\hline South region & 0.322 & 0.349 \\
\hline Midwest region & 0.326 & 0.364 \\
\hline Other region & 0.104 & 0.246 \\
\hline Health plan (versus employer) & 0.068 & 0.252 \\
\hline Three-tier plan (versus two-tier) & 0.686 & 0.464 \\
\hline \multicolumn{3}{|l|}{ Two-tier member cost sharing ${ }^{\dagger}$} \\
\hline Retail coinsurance & 0.495 & 0.463 \\
\hline Retail generic OOP cost $(\$)$ & 7.25 & 3.45 \\
\hline Retail brand OOP cost $(\$)$ & 23.33 & 10.86 \\
\hline Mail-retail generic OOP cost ratio & 2.095 & 1.051 \\
\hline Mail-retail brand OOP cost ratio & 1.775 & 0.871 \\
\hline \multicolumn{3}{|l|}{ Three-tier member cost sharing } \\
\hline Retail coinsurance & 0.202 & 0.373 \\
\hline Retail generic OOP cost $(\$)$ & 8.79 & 3.67 \\
\hline Retail $\mathrm{P}$ brand OOP cost $(\$)$ & 22.78 & 7.11 \\
\hline Retail NP brand OOP cost (\$) & 36.75 & 12.04 \\
\hline Mail-retail generic OOP cost ratio & 2.115 & 1.346 \\
\hline Mail-retail $\stackrel{\mathrm{P}}{\text { brand }} \mathrm{OOP}$ cost ratio & 1.827 & 0.488 \\
\hline Mail-retail NP brand OOP cost ratio & 1.846 & 0.584 \\
\hline \multicolumn{3}{|l|}{ Other pharmacy benefit design elements } \\
\hline Retail deductible & 0.109 & 0.288 \\
\hline Retail dispense as written penalty (physician) & 0.224 & 0.398 \\
\hline Retail dispense as written penalty (patient) & 0.326 & 0.440 \\
\hline Retail maximum allowable benefit & 0.099 & 0.284 \\
\hline Retail maximum out-of-pocket & 0.056 & 0.215 \\
\hline Mandatory mail & 0.168 & 0.359 \\
\hline
\end{tabular}

Note: All means and standard deviation values are expressed as proportions unless otherwise indicated. *Prescription drug utilization measures calculated using 30-day supply equivalents (i.e., 1 mail $\mathrm{rx}=3$ retail $\mathrm{rxs}$ ).

${ }^{\dagger}$ Presented are member cost-sharing means and standard deviations specific to two-tier plans. ${ }^{\ddagger}$ Presented are member cost-sharing means and standard deviations specific to three-tier plans. NP brand, nonpreferred brand; OOP, out-of-pocket; P brand, preferred brand; PMPQ, per member per quarter; SD, standard deviation. 
result of both declining brand utilization (1.94-1.54 rxs per member per quarter) and inclining generic utilization (1.71-2.07 rxs per member per quarter). Finally, although MDR increased from 31 percent in Q1/2005 to 35 percent in Q4/2007, the trend over the 3-year period was not linear. Appendix Table S1 provides these time-specific results for the dependent variables.

Tables 2 and 3 present selected coefficients from linear fixed effects models of generic utilization, brand utilization, and GDR (Table 2), as well as retail utilization, mail utilization, and MDR (Table 3). The complete output from the models is provided in Appendix Tables S2 and S3. Although the estimated coefficients for the dichotomous benefit design variables can be readily interpreted as marginal effects, evaluating the results for the continuous measures is not as straightforward. Because retail OOP costs and mailretail OOP cost ratios entered the equations as both first-order and squared regressors, their effects are by definition nonlinear. To assist in interpretation, Table 4 presents predicted values for the dependent variables where the OOP costs measures are set equal to their 10th, 50th, and 90th percentiles (one at a time), while all other regressors are held constant at their means. Also included in this table is a column representing the predicted number of all rxs PMPQ (i.e., generic rxs+brand rxs; retail rxs+mail rxs).

Several noteworthy results emerged for the member cost-sharing variables. First, relative to retail brand OOP costs, retail generic OOP costs had a small marginal effect on GDR. For example, plans with retail generic OOP costs at the 10th percentile ( $\$ 4.35$ for two tier, $\$ 4.54$ for three tier) were predicted to have GDRs within 0.007 of plans with retail generic OOP costs at the 90th percentile ( $\$ 11.28$ for two tier, $\$ 13.61$ for three tier). The slight decrease in GDR among two-tier plans was largely associated with a significant increase in the number of brand rxs PMPQ, while the lower GDR in three-tier designs was primarily the result of a significant decline in absolute generic utilization. Utilization of generics is perhaps more responsive to generic OOP costs in three-tier plans because brand versions of generic drugs usually have nonpreferred formulary status with higher cost sharing.

The results for retail brand OOP costs are more compelling. Among two-tier plans, retail brand OOP cost was positively and significantly related to GDR. A change in this patient OOP cost from $\$ 10.00$ (10th percentile) to $\$ 34.16$ (90th percentile) would translate into a GDR increase of 0.035 through a reduction in brand utilization from 2.076 to 1.689 . This decline in brand use is not offset by an increase in generic use; therefore, overall utilization decreases by 8.9 percent. In three-tier plans where brands are split into 
Table 2: Linear Fixed Effects Models of Generic and Brand Prescription Drug Utilization ${ }^{\dagger}(N=1,074)$

\begin{tabular}{|c|c|c|c|}
\hline Variable & $\begin{array}{l}\text { Number } \\
\text { of Generic } \\
\text { rxs PMPQ }\end{array}$ & $\begin{array}{c}\text { Number of } \\
\text { Brand rxs } \\
\text { PMPQ }\end{array}$ & $\begin{array}{c}\text { Generic } \\
\text { Dispensing } \\
\text { Rate (GDR) }\end{array}$ \\
\hline \multicolumn{4}{|l|}{ Two-tier member cost sharing } \\
\hline Retail coinsurance & $\begin{array}{c}-0.14676^{* * * * *} \\
(0.05355)\end{array}$ & $\begin{array}{r}-0.06591 \\
(0.07022)\end{array}$ & $\begin{array}{r}-0.00369^{*} \\
(0.00218)\end{array}$ \\
\hline Retail generic OOP cost & $\begin{array}{c}0.04089 \\
(0.02779)\end{array}$ & $\begin{array}{l}0.08753^{* * * *} \\
(0.02841)\end{array}$ & $\begin{array}{c}0.00203 \\
(0.00144)\end{array}$ \\
\hline Retail generic OOP cost squared & $\begin{array}{c}-0.00191 \\
(0.00158)\end{array}$ & $\begin{array}{c}-0.00369^{* * *} \\
(0.00167)\end{array}$ & $\begin{array}{c}-0.00019^{* *} \\
(0.00007)\end{array}$ \\
\hline Retail brand OOP cost & $\begin{array}{r}-0.00068 \\
(0.00318)\end{array}$ & $\begin{array}{c}-0.02626^{* * * * *} \\
(0.00371)\end{array}$ & $\begin{array}{l}0.00185^{\text {***** }} \\
(0.00048)\end{array}$ \\
\hline Retail brand OOP cost squared & $\begin{array}{c}0.00005 \\
(0.00004)\end{array}$ & $\begin{array}{l}0.00023^{* * * *} \\
(0.00005)\end{array}$ & $\begin{array}{r}-0.00001 \\
(0.00001)\end{array}$ \\
\hline Mail-retail generic OOP cost ratio & $\begin{array}{c}0.07409 \\
(0.06215)\end{array}$ & $\begin{array}{c}0.08903 \\
(0.05609)\end{array}$ & $\begin{array}{l}0.00784^{* * *} \\
(0.00366)\end{array}$ \\
\hline Mail-retail generic OOP cost ratio squared & $\begin{array}{r}-0.00607 \\
(0.00572)\end{array}$ & $\begin{array}{c}-0.01230^{* * *} \\
(0.00585)\end{array}$ & $\begin{array}{c}-0.00071^{* *} \\
(0.00032)\end{array}$ \\
\hline Mail-retail brand OOP cost ratio & $\begin{array}{c}-0.20046^{* * * * *} \\
(0.04560)\end{array}$ & $\begin{array}{c}-0.29762^{* * * *} \\
(0.05356)\end{array}$ & $\begin{array}{l}0.02063^{* * * *} \\
(0.00421)\end{array}$ \\
\hline Mail-retail brand OOP cost ratio squared & $\begin{array}{l}0.01040 \text { ***** } \\
(0.00245)\end{array}$ & $\begin{array}{l}0.01442^{\text {***** }} \\
(0.00270)\end{array}$ & $\begin{array}{c}-0.00093^{\text {***** }} \\
(0.00019)\end{array}$ \\
\hline Three-tier member cost sharing ${ }^{\S}$ & & & \\
\hline Retail coinsurance & $\begin{array}{r}-0.03202 \\
(0.04646)\end{array}$ & $\begin{array}{r}-0.01371 \\
(0.04242)\end{array}$ & $\begin{array}{c}0.00237 \\
(0.00178)\end{array}$ \\
\hline Retail generic OOP cost & $\begin{array}{c}-0.02924^{* * * * *} \\
(0.00893)\end{array}$ & $\begin{array}{r}-0.00117 \\
(0.00796)\end{array}$ & $\begin{array}{l}0.00016 \\
(0.00024)\end{array}$ \\
\hline Retail generic OOP cost squared & $\begin{array}{l}0.00046^{* * * * *} \\
(0.00015)\end{array}$ & $\begin{array}{r}-0.00000 \\
(0.00013)\end{array}$ & $\begin{array}{l}0.00001^{*} \\
(0.00001)\end{array}$ \\
\hline Retail P brand OOP cost & $\begin{array}{c}0.01825 \\
(0.01418)\end{array}$ & $\begin{array}{c}0.00812 \\
(0.01736)\end{array}$ & $\begin{array}{c}-0.00136^{* * *} \\
(0.00066)\end{array}$ \\
\hline Retail P brand OOP cost squared & $\begin{array}{c}-0.00046^{* *} \\
(0.00023)\end{array}$ & $\begin{array}{r}-0.00036 \\
(0.00029)\end{array}$ & $\begin{array}{l}0.00004^{\text {****** }} \\
(0.00001)\end{array}$ \\
\hline Retail NP brand OOP cost & $\begin{array}{c}0.00539 \\
(0.00514)\end{array}$ & $\begin{array}{r}-0.01147^{*} \\
(0.00605)\end{array}$ & $\begin{array}{l}0.00220^{\text {***** }} \\
(0.00033)\end{array}$ \\
\hline Retail NP brand OOP cost squared & $\begin{array}{r}-0.00005 \\
(0.00004)\end{array}$ & $\begin{array}{r}0.00009^{*} \\
(0.00005)\end{array}$ & $\begin{array}{c}-0.00002^{\text {***** }} \\
(0.00000)\end{array}$ \\
\hline Mail-retail generic OOP cost ratio & $\begin{array}{c}0.00711 \\
(0.01784)\end{array}$ & $\begin{array}{c}0.03365^{*} \\
(0.01884)\end{array}$ & $\begin{array}{c}-0.00224 \\
(0.00152)\end{array}$ \\
\hline Mail-retail generic OOP cost ratio squared & $\begin{array}{c}-0.00155^{* *} \\
(0.00066)\end{array}$ & $\begin{array}{c}-0.00281^{* * * * *} \\
(0.00103)\end{array}$ & $\begin{array}{l}0.00024^{\text {****** }} \\
(0.00008)\end{array}$ \\
\hline Mail-retail $\mathrm{P}$ brand OOP cost ratio & $\begin{array}{r}-0.18369 \\
(0.24897)\end{array}$ & $\begin{array}{r}-0.33670 \\
(0.25856)\end{array}$ & $\begin{array}{l}0.01737^{* * * *} \\
(0.00569)\end{array}$ \\
\hline Mail-retail P brand OOP cost ratio squared & $\begin{array}{c}0.05462 \\
(0.06402)\end{array}$ & $\begin{array}{c}0.06557 \\
(0.06305)\end{array}$ & $\begin{array}{c}-0.00374^{* *} \\
(0.00149)\end{array}$ \\
\hline
\end{tabular}


Table 2. Continued

\begin{tabular}{lccc}
\hline & $\begin{array}{c}\text { Number } \\
\text { of Generic } \\
\text { rxs PMPQ }\end{array}$ & $\begin{array}{c}\text { Number of } \\
\text { Brand rxs } \\
\text { PMPQ }\end{array}$ & $\begin{array}{c}\text { Generic } \\
\text { Dispensing } \\
\text { Rate (GDR) }\end{array}$ \\
\hline Mail-retail NP brand OOP cost ratio & -0.18311 & 0.09793 & $-0.01081^{* * *}$ \\
Mail-retail NP brand OOP cost ratio squared & $(0.14503)$ & $(0.19889)$ & $(0.00461)$ \\
& 0.02352 & -0.03603 & $0.00371^{* * * *}$ \\
Other pharmacy benefit design elements & $(0.02630)$ & $(0.03585)$ & $(0.00090)$ \\
Retail deductible & $-0.14751^{* * * *}$ & $-0.12812^{* * * *}$ & -0.00042 \\
Retail dispense as written penalty (physician) & $(0.03862)$ & $(0.02930)$ & $(0.00241)$ \\
& 0.00169 & -0.04776 & $0.01146^{* * * *}$ \\
Retail dispense as written penalty (patient) & $(0.02049)$ & $(0.03002)$ & $(0.00191)$ \\
Retail maximum allowable benefit & 0.05308 & 0.07999 & $0.00319^{* * *}$ \\
Retail maximum out-of-pocket & $(0.04452)$ & $(0.05108)$ & $(0.00163)$ \\
& $0.06779^{* * * * *}$ & $0.05775^{* * * * *}$ & $0.01356^{* * * *}$ \\
Mandatory mail & $(0.00847)$ & $(0.01371)$ & $(0.00125)$ \\
& -0.02789 & -0.10436 & -0.00291 \\
& $(0.12390)$ & $(0.11194)$ & $(0.00343)$ \\
\hline
\end{tabular}

Note: Presented are coefficient estimates with robust Driscoll-Kraay standard errors in parentheses. Included in models but not reported are 11 plan sponsor characteristic variables, 11 time dummies, and a constant.

Statistical significance denoted as:

$* * * * p<.01$.

$* * p<.05$.

$* p<.10$.

${ }^{\dagger}$ Prescription drug utilization measures calculated using 30-day supply equivalents (i.e., 1 mail $\mathrm{rx}=3$ retail $\mathrm{rxs})$.

${ }^{\ddagger}$ Coefficients and standard errors are of member cost-sharing variables interacted with two-tier plan indicator.

${ }^{\S}$ Coefficients and standard errors are of member cost-sharing variables interacted with three-tier plan indicator.

NP brand, nonpreferred brand; OOP, out-of-pocket; P brand, preferred brand; PMPQ per member per quarter.

preferred and nonpreferred categories, an increase in the retail preferred brand OOP cost from $\$ 15.00$ (10th percentile) to $\$ 30.73$ (90th percentile) would be associated with a 0.011 increase in GDR on both lower generic and brand utilization. Raising the retail nonpreferred brand OOP cost from $\$ 22.02$ to $\$ 50.00$ would lead to an incline in GDR of 0.020 . In this case, the increase in GDR would come from decreasing brand utilization ( -7.2 percent) and increasing generic utilization $(+2.9$ percent). This result suggests that some generic substitution takes place in response to higher retail nonpreferred 
Table 3: Linear Fixed Effects Models of Retail and Mail Prescription Drug Utilization $^{\dagger}(N=1,074)$

\begin{tabular}{|c|c|c|c|}
\hline Variable & $\begin{array}{c}\text { Number of } \\
\text { Retail rxs } \\
P M P Q\end{array}$ & $\begin{array}{c}\text { Number of } \\
\text { Mail rxs } \\
P M P Q\end{array}$ & $\begin{array}{c}\text { Mail } \\
\text { Distribution } \\
\text { Rate (MDR) }\end{array}$ \\
\hline \multicolumn{4}{|l|}{ Two-tier member cost sharing } \\
\hline Retail coinsurance & $\begin{array}{c}-0.24809^{* * * *} \\
(0.06691)\end{array}$ & $\begin{array}{c}0.03542 \\
(0.07997)\end{array}$ & $\begin{array}{l}0.04002^{* * * * *} \\
(0.01090)\end{array}$ \\
\hline Retail generic OOP cost & $\begin{array}{c}0.05502 \\
(0.03934)\end{array}$ & $\begin{array}{l}0.07340 * * * * \\
(0.02619)\end{array}$ & $\begin{array}{r}-0.00041 \\
(0.00446)\end{array}$ \\
\hline Retail generic OOP cost squared & $\begin{array}{r}-0.00435^{*} \\
(0.00234)\end{array}$ & $\begin{array}{c}-0.00124 \\
(0.00147)\end{array}$ & $\begin{array}{l}0.00070^{\text {*** }} \\
(0.00028)\end{array}$ \\
\hline Retail brand OOP cost & $\begin{array}{c}-0.02957 \text { **** } \\
(0.00607)\end{array}$ & $\begin{array}{c}0.00263 \\
(0.00346)\end{array}$ & $\begin{array}{c}0.00139 \\
(0.00100)\end{array}$ \\
\hline Retail brand OOP cost squared & $\begin{array}{l}0.00039^{* * * * *} \\
(0.00011)\end{array}$ & $\begin{array}{c}-0.00011^{* * *} \\
(0.00005)\end{array}$ & $\begin{array}{r}-0.00003^{*} \\
(0.00002)\end{array}$ \\
\hline Mail-retail generic OOP cost ratio & $\begin{array}{l}0.13557^{* * * * *} \\
(0.04438)\end{array}$ & $\begin{array}{c}0.02756 \\
(0.07736)\end{array}$ & $\begin{array}{r}-0.01021^{*} \\
(0.00528)\end{array}$ \\
\hline Mail-retail generic OOP cost ratio squared & $\begin{array}{c}-0.01581^{* * * * *} \\
(0.00447)\end{array}$ & $\begin{array}{r}-0.00256 \\
(0.00792)\end{array}$ & $\begin{array}{l}0.00190^{* * *} \\
(0.00074)\end{array}$ \\
\hline Mail-retail brand OOP cost ratio & $\begin{array}{c}-0.20627^{* * * *} \\
(0.04160)\end{array}$ & $\begin{array}{c}-0.29181^{* * * *} \\
(0.06907)\end{array}$ & $\begin{array}{c}-0.04426^{* * * *} \\
(0.01321)\end{array}$ \\
\hline Mail-retail brand OOP cost ratio squared & $\begin{array}{l}0.01168^{\text {***** }} \\
(0.00192)\end{array}$ & $\begin{array}{l}0.01314^{* * * * *} \\
(0.00367)\end{array}$ & $\begin{array}{l}0.00170^{* * *} \\
(0.00069)\end{array}$ \\
\hline Three-tier member cost sharing ${ }^{\S}$ & & & \\
\hline Retail coinsurance & $\begin{array}{c}0.04413 \\
(0.07548)\end{array}$ & $\begin{array}{r}-0.08987 \\
(0.05907)\end{array}$ & $\begin{array}{r}-0.01150^{*} \\
(0.00669)\end{array}$ \\
\hline Retail generic OOP cost & $\begin{array}{r}-0.00863 \\
(0.01246)\end{array}$ & $\begin{array}{c}-0.02178^{* * * * *} \\
(0.00545)\end{array}$ & $\begin{array}{c}-0.00502^{* * * * *} \\
(0.00095)\end{array}$ \\
\hline Retail generic OOP cost squared & $\begin{array}{r}-0.00010 \\
(0.00023)\end{array}$ & $\begin{array}{l}0.00056^{* * * *} \\
(0.00008)\end{array}$ & $\begin{array}{l}0.00020^{* * * *} \\
(0.00003)\end{array}$ \\
\hline Retail P brand OOP cost & $\begin{array}{r}-0.02413 \\
(0.01643)\end{array}$ & $\begin{array}{l}0.05051^{* * * *} \\
(0.01707)\end{array}$ & $\begin{array}{l}0.01026^{* * * *} \\
(0.00160)\end{array}$ \\
\hline Retail P brand OOP cost squared & $\begin{array}{c}0.00004 \\
(0.00028)\end{array}$ & $\begin{array}{c}-0.00086^{* * * * *} \\
(0.00027)\end{array}$ & $\begin{array}{c}-0.00015^{\text {**** }} \\
(0.00002)\end{array}$ \\
\hline Retail NP brand OOP cost & $\begin{array}{c}0.00945 \\
(0.00679)\end{array}$ & $\begin{array}{c}-0.01553^{* * * * *} \\
(0.00601)\end{array}$ & $\begin{array}{c}-0.00244^{* * * *} \\
(0.00051)\end{array}$ \\
\hline Retail NP brand OOP cost squared & $\begin{array}{r}-0.00004 \\
(0.00006)\end{array}$ & $\begin{array}{l}0.00009^{* * *} \\
(0.00004)\end{array}$ & $\begin{array}{l}0.00001^{* * * * *} \\
(0.00000)\end{array}$ \\
\hline Mail-retail generic OOP cost ratio & $\begin{array}{c}0.03622 \\
(0.02406)\end{array}$ & $\begin{array}{c}0.00454 \\
(0.01779)\end{array}$ & $\begin{array}{c}-0.00553^{* * * * *} \\
(0.00160)\end{array}$ \\
\hline Mail-retail generic OOP cost ratio squared & $\begin{array}{c}-0.00229^{* * * * *} \\
(0.00084)\end{array}$ & $\begin{array}{r}-0.00207 \\
(0.00146)\end{array}$ & $\begin{array}{r}-0.00000 \\
(0.00016)\end{array}$ \\
\hline Mail-retail P brand OOP cost ratio & $\begin{array}{c}0.17569 \\
(0.28698)\end{array}$ & $\begin{array}{c}-0.69608^{* * * * *} \\
(0.24399)\end{array}$ & $\begin{array}{c}-0.08708^{\text {****** }} \\
(0.00843)\end{array}$ \\
\hline Mail-retail P brand OOP cost ratio squared & $\begin{array}{r}-0.03378 \\
(0.06491)\end{array}$ & $\begin{array}{l}0.15397 * * \\
(0.06794)\end{array}$ & $\begin{array}{l}0.02119^{* * * *} \\
(0.00443)\end{array}$ \\
\hline
\end{tabular}


Table 3. Continued

\begin{tabular}{lccc}
\hline & $\begin{array}{c}\text { Number of } \\
\text { Retail rxs } \\
\text { Variable }\end{array}$ & $\begin{array}{c}\text { Number of } \\
\text { Mail rxs } \\
\text { PMPQ }\end{array}$ & $\begin{array}{c}\text { Mail } \\
\text { Distribution } \\
\text { Rate }(M D R)\end{array}$ \\
\hline Mail-retail NP brand OOP cost ratio & $-0.50486^{* *}$ & $0.41969^{* * * *}$ & $0.08572^{* * * *}$ \\
Mail-retail NP brand OOP cost ratio squared & $(0.30047)$ & $(0.10726)$ & $(0.01556)$ \\
& $0.10245^{* * *}$ & $-0.11496^{* * * *}$ & $-0.02268^{* * * * *}$ \\
Other pharmacy benefit design elements & $(0.04926)$ & $(0.02967)$ & $(0.00409)$ \\
Retail deductible & & & \\
& $-0.10245^{* * *}$ & $-0.17318^{* * * *}$ & $-0.02317^{* * * * *}$ \\
Retail dispense as written penalty (physician) & $(0.04156)$ & $(0.02766)$ & $(0.00372)$ \\
& $-0.13314^{* * * *}$ & $0.08707^{* * * *}$ & $0.04351^{* * * *}$ \\
Retail dispense as written penalty (patient) & $(0.02987)$ & $(0.03039)$ & $(0.00701)$ \\
& -0.05743 & $0.19050^{* * * *}$ & $0.04367^{* * * *}$ \\
Retail maximum allowable benefit & $(0.04050)$ & $(0.06432)$ & $(0.00864)$ \\
Retail maximum out-of-pocket & 0.01071 & $0.11482^{* * * *}$ & $0.01881^{* * * *}$ \\
Mandatory mail & $(0.03463)$ & $(0.03229)$ & $(0.00666)$ \\
& 0.01930 & -0.15155 & -0.00866 \\
& $(0.11792)$ & $(0.12804)$ & $(0.00613)$ \\
& $-0.26787^{* * * *}$ & $0.28661^{* * * *}$ & $0.08597^{* * * *}$ \\
& $(0.02059)$ & $(0.02914)$ & $(0.00855)$ \\
\hline
\end{tabular}

Notes: Presented are coefficient estimates with robust Driscoll-Kraay standard errors in parentheses. Included in models but not reported are 11 plan sponsor characteristic variables, 11 time dummies, and a constant.

Statistical significance denoted as:

$* * * * 0.01$.

$* * p<.05$.

$* p<.10$.

${ }^{\dagger}$ Prescription drug utilization measures calculated using 30-day supply equivalents (i.e., 1 mail $\mathrm{rx}=3$ retail $\mathrm{rxs})$.

${ }^{\ddagger}$ Coefficients and standard errors are of member cost-sharing variables interacted with two-tier plan indicator.

${ }^{\S}$ Coefficients and standard errors are of member cost-sharing variables interacted with three-tier plan indicator.

NP brand, nonpreferred brand; OOP, out-of-pocket; P brand, preferred brand; PMPQ per member per quarter.

brand OOP costs (i.e., often multisource brands with generic equivalents), but switching to alternative, nonequivalent generics may be less common.

Besides substituting between generics and brands, individuals can also respond to cost-share changes by altering their prescription delivery channel. As expected, most model results indicate that as retail OOP costs increase, retail utilization decreases yet does not necessarily shift to mail service. For example, in two-tier plans, a higher retail generic OOP cost prompts a 


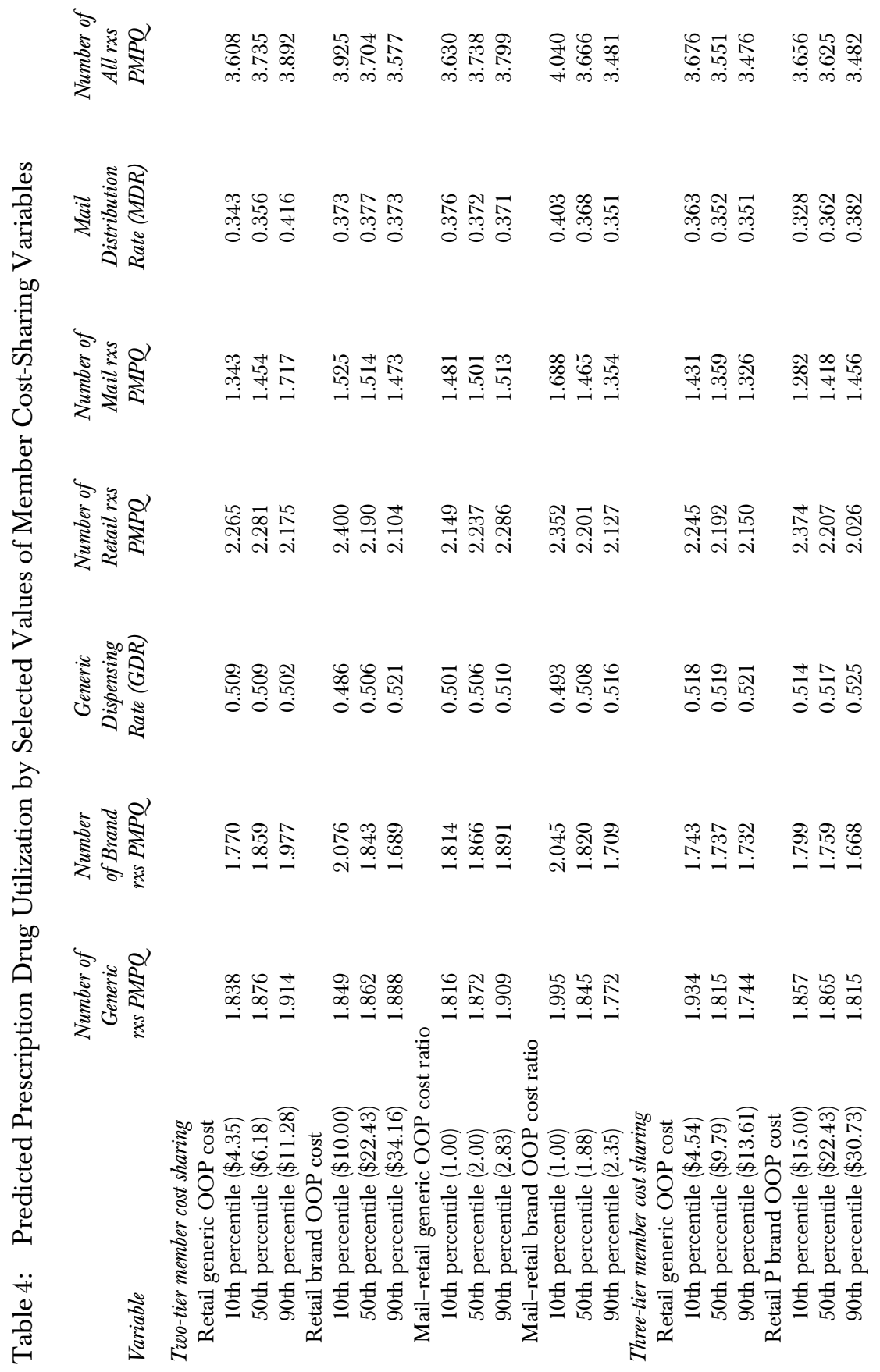




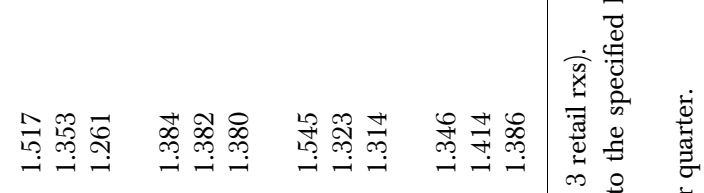

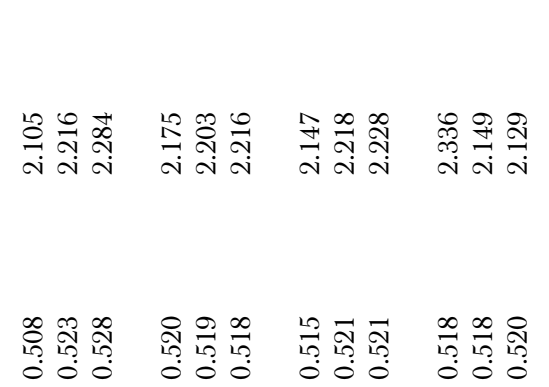

is 8 क

希

咅

है:

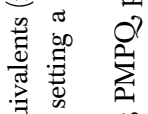

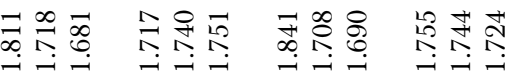

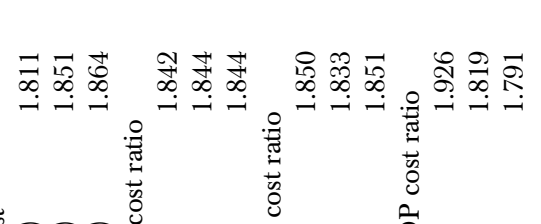

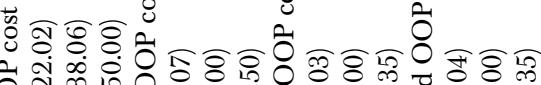

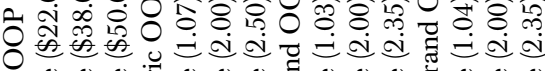

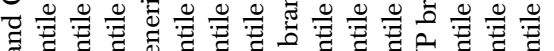

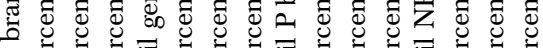

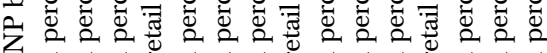

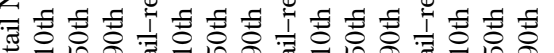

㐘

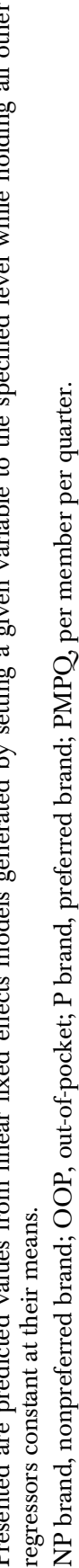


reduction in the retail generic utilization rate, an increase in mail generic use, and consequently a substantial incline in MDR. Among three-tier plan sponsors, however, the drop in retail fills is not accompanied by a lift in mail order prescriptions. Similarly, raising the retail brand OOP cost in a two-tier design, likely results in treatment discontinuation, since both the number of brand and retail rxs PMPQ decline without comparable increases in either the number of generics or mail prescriptions filled PMPQ.

In theory, mail-retail OOP cost ratios should have significant impacts on the absolute and relative use of retail and mail delivery options. Ratios equal to or greater than three would pose no financial incentive for the member to fill at mail versus retail. On the other hand, ratios $<3$ would suggest individuals might receive 90 days of medication supply for less-on a per-day basis-at mail than at retail. Findings are mixed, however, for these variables. Mail utilization is largely unchanged or slightly higher when the mail-retail generic OOP cost ratio is raised from the 10th to the 90th percentile. Conversely, for brands where the magnitude of cost savings can be dramatic for the member, the relative OOP cost for mail compared with retail had a greater effect. For example, an increase in the mail-retail preferred brand OOP cost ratio from 1.03 to 2.35 would be associated with a decline in the mail utilization rate from 1.545 to 1.314 rxs PMPQ or -15 percent. Only a portion of this reduced mail volume appears to "return" to retail fulfillment, resulting in a decline in the overall utilization rate.

In addition to cost sharing, the multivariate models also controlled for other pharmacy benefit design elements. Several results are worth noting. First, across the board, having a retail deductible was associated with significantly lower prescription drug utilization, approximately 0.276 fewer rxs PMPQ. Second, unexpectedly, having a retail MAB led to a significant increase in the use of mail service and, therefore, overall utilization. Third, retail DAW penalties were significantly related to lower rates of retail use, higher rates of mail use, and MDRs larger by $>4$ percentage points. Finally, mandatory mail was quite effective at shifting retail prescriptions $(-0.268 \mathrm{PMPQ})$ to mail $(+0.287 \mathrm{PMPQ})$, resulting in an almost 9 percentage point increase in MDR.

\section{DISCUSSION}

Several key findings on the relationships between pharmacy benefit design and prescription drug utilization emerged from the present study. First, as expected, member cost-share variables were generally associated with 
changes in the outcomes examined. In many cases, these utilization measures were more sensitive to brand OOP costs than generic OOP costs. This suggests that plan sponsors intent on lowering pharmacy costs by encouraging appropriate use of generics and mail service may opt to raise brand copays rather than lower generic copays. Second, estimates support the nonlinear effects of retail OOP costs and mail-retail OOP cost ratios on prescription drug utilization. Prior studies have either assumed linear relationships or have modeled cost-sharing variables on the log scale to yield elasticity estimates. The present analysis offers an alternative framework that supports future work on the functional forms imposed in insurance design research.

Finally, pharmacy benefit designs can be complex. In addition to copayment amounts and coinsurance rates, plan sponsors have other mechanisms by which to encourage desired member behaviors. DAWs, for example, shift costs to consumers when they demand brands over therapeutically equivalent generics. The present study demonstrates the effectiveness of these other policies at driving generic dispensing and mail service use. Therefore, previous estimates of the impact of OOP costs on prescription drug utilization may be biased if other prescription benefit elements are omitted, particularly in cross-sectional analyses. Endogeneity might also be an issue if secular trends are ignored. For example, GDR and MDR were both on the rise throughout the study period. If plan sponsors based benefit design decisions on the expected generic drug pipeline-a possible explanation for inclining GDRmarginal effect estimates for those characteristics might be biased in the absence of time trend controls.

There are limitations of the present study. First, despite the inclusion of important covariates and the leveraged use of panel data, the potential endogeneity of pharmacy benefit design remains. Using the fixed effects method, unmeasured factors correlated with elements of benefit design and also prescription drug utilization could still lead to biased estimates if those unobservables vary over time. This would be the case, for example, if a client's average health status substantially changed from one period to the next, and if that case-mix adjustment coincided with an amendment to pharmacy benefit design. Formulary changes such as the tier placement of highly utilized drugs might be another concern; however, most clients in this study adopted the standard CVS Caremark preferred drug list. A second limitation pertains to the unit of observation. Because this was a plan sponsor-level analysis, one cannot conclude that patient-level effects would be comparable to the results presented. It is well known that downward, cross-level inference may suffer from problems of "ecological fallacy" (Firebaugh 1978). Third, copays across 
tiers may be correlated, thereby increasing the possibility of multicollinearity in multivariate models. Although this does not appear to be an issue in the present study with regard to generic and (preferred) brand OOP costs-the correlation between the retail generic OOP cost and the retail brand OOP cost was 0.341 in two-tier plans and 0.387 in three-tier plans-it may be problematic in three-tier designs where the retail preferred brand OOP cost is highly correlated with the retail nonpreferred brand OOP cost $(\rho=0.721)$. Specific coefficient estimates pertaining to these variables should be viewed with appropriate caution.

Pharmacy benefit designs employ financial incentives to moderate and direct consumer purchasing of prescription drugs. When faced with the OOP cost for a medication at a retail pharmacy, an individual may decide to discontinue or not initiate therapy, change to a lower cost alternative (e.g., preferred brand, generic), select a less expensive delivery channel (e.g., mail service), or choose to fill the prescription regardless of the OOP cost. All of these choices directly impact the pharmacy expenditures of the plan sponsor. Therefore, GDR and MDR are often viewed as key performance indicators of pharmacy benefit designs and PBMs. Greater use of generics relative to brands and mail relative to retail will in most cases translate into lower average costs per day of therapy supplied. Although important, optimization of pharmacy benefit design to maximize relative pharmacy utilization metrics should not ignore absolute utilization. After all, GDR can rise with an increasing numerator (generic utilization) or with a decreasing denominator (brand utilization). Reductions in pharmacy use may lead to adverse health events and increased utilization of other more expensive health services. Ultimately, plan sponsors are left with the challenge of implementing benefit designs, which eliminate moral hazard while minimizing total health care costs.

\section{ACKNOWLEDGMENTS}

Joint Acknowledgments/Disclosure Statement: The authors are grateful for the thoughtful and valuable suggestions of two anonymous reviewers, as well as the editors; the manuscript was much improved by their contributions. We appreciate the data extraction and manipulation work by Stephen E. Bittner, George Collier, Mark Ward, and Christopher Young.

Disclosures: This study was funded entirely by CVS Caremark, where both authors are full-time employees. 


\section{REFERENCES}

Brixner, D. I., V. N. Joish, G. M. Oderda, S. G. Avey, D. M. Hanson, and H. E. Cannon. 2007. "Effects of Benefit Design Change across 5 Disease States." American Journal of Managed Care 13 (2): 370-6.

Centers for Medicare and Medicaid Services (CMS). 2006. "Part D Sponsors Generic Dispensing Rate (GDR) Performance Metrics" [accessed on July 9, 2008]. Available at http://www.cms.hhs.gov/PrescriptionDrugCovContra/downloads/ MemoGDRPerfMetric_11.09.06.pdf

Centers for Medicare and Medicaid Services (CMS). 2008. "National Health Expenditure Accounts, Historical” [accessed on January 24, 2008]. Available at http:// www.cms.hhs.gov/NationalHealthExpendData/

Chernew, M. E., M. R. Shah, A. Wegh, S. N. Rosenberg, I. A. Juster, A. B. Rosen, M. C. Sokol, K. Yu-Isenberg, and A. M. Fendrick. 2008. "Impact of Decreasing Copayments on Medication Adherence within a Disease Management Environment." Health Affairs 27 (1): 103-12.

Cutler, D. M., and R. J. Zeckhauser. 2000. "The Anatomy of Health Insurance." In Handbook of Health Economics, Vol. 1A, 1st Edition, edited by A. J. Culyer and J. P. Newhouse, pp 563-643. Amsterdam: Elsevier.

Driscoll, J., and A. C. Kraay. 1998. "Consistent Covariance Matrix Estimation with Spatially Dependent Data." Review of Economics and Statistics 80: 549-60.

Drukker, D. M. 2003. "Testing for Serial Correlation in Linear Panel-Data Models." Stata Journal 3 (2): 168-77.

Ellis, R. P., and W. G. Manning. 2007. "Optimal Health Insurance for Prevention and Treatment." Journal of Health Economics 26: 1128-50.

Fairman, K. A., B. R. Motheral, and R. R. Henderson. 2003. "Retrospective, LongTerm Follow-Up Study of the Effect of a Three-Tier Prescription Drug Copayment System on Pharmaceutical and Other Medical Utilization and Costs." Clinical Therapeutics 25 (12): 3147-61.

Firebaugh, G. 1978. "A Rule for Inferring Individual-Level Relationships from Aggregate Data." American Sociological Review 43 (4): 557-72.

Gemmill, M. C., J. Costa-Font, and A. McGuire. 2007. "In Search of a Corrected Prescription Drug Elasticity Estimate: A Meta-Regression Approach." Health Economics 16: 627-43.

Gilman, B. H., and J. Kautter. 2007. "Consumer Response to Dual Incentives under Multitiered Prescription Drug Formularies." American Journal of Managed Care 13 (2): 353-9.

2008. "Impact of Multitiered Copayments on the Use and Cost of Prescription Drugs among Medicare Beneficiaries." Health Services Research 43 (2): 478-95.

Goldman, D. P., G. F. Joyce, J. J. Escarce, J. E. Pace, M. D. Solomon, M. Laouri, P. B. Landsman, and S. M. Teutsch. 2004. "Pharmacy Benefits and the Use of Drugs by the Chronically III." Journal of the American Medical Association 291 (19): 2344-50.

Greene, W. H. 2003. Econometric Analysis. 5th Edition. Upper Saddle River, NJ: Prentice Hall.

Hausman, J. A. 1978. “Specification Tests in Econometrics.” Econometrica 46: 1251-71. 
Hoechle, D. 2007. "Robust Standard Errors for Panel Regressions with Cross-Sectional Dependence." Stata Journal 7 (3): 281-312.

Huskamp, H. A., P. A. Deverka, A. M. Epstein, R. S. Epstein, K. A. McGuigan, and R. G. Frank. 2003. "The Effect of Incentive-Based Formularies on PrescriptionDrug Utilization and Spending." New England Journal of Medicine 349: 2224-32.

Huskamp, H. A., P. A. Deverka, M. B. Landrum, R. S. Epstein, and K. A. McGuigan. 2007. "The Effect of Three-Tier Formulary Adoption on Medication Continuation and Spending among Elderly Retirees." Health Services Research 42 (5): 1926-42.

IMS Health. 2008. "Channel Distribution by U.S. Dispensed Prescriptions, IMS National Prescription Audit Plus" [accessed on July 1, 2008]. Available at http://imshealth.com/vgn/images/portal/CIT_40000873/39/53/

834329692007\%20Channel $\% 20$ Distribution $\% 20$ by $\% 20$ RXs.pdf

Kaiser Family Foundation and Health Research and Educational Trust (KFF/HRET). 2007. "Employer Health Benefits 2007 Annual Survey" [accessed on January 24, 2008]. Available at http://www.kff.org/insurance/7672

Landon, B. E., M. B. G. Rosenthal, S. T. Normand, C. Spetell, A. Lessler, H. R. Underwood, and J. P. Newhouse. 2007. "Incentive Formularies and Changes in Prescription Drug Spending." American Journal of Managed Care 200713 (2): 360-9.

Landsman, P. B., W. Yu, X. F. Liu, S. M. Teutsch, and M. L. Berger. 2005. "Impact of 3-Tier Prescription Benefit Design and Increased Consumer Cost-Sharing on Drug Utilization." American Journal of Managed Care 11: 621-8.

Leibowitz, A., W. Manning, and J. P. Newhouse. 1985. "The Demand for Prescription Drugs as a Function of Cost-Sharing." Social Science and Medicine 21: 1063-9.

Mager, D. E., and E. R. Cox. 2007. "Relationship between Generic and PreferredBrand Prescription Copayment Differentials and Generic Fill Rate.” American Journal of Managed Care 13 (2): 347-52.

Manning, W. G., J. P. Newhouse, N. Duan, E. B. Keeler, A. Leibowitz, and M. S. Marquis. 1987. "Health Insurance and the Demand for Medical Care: Evidence from a Randomized Experiment." American Economic Review 77: 251-77.

Motheral, B., and K. A. Fairman. 2001. "Effect of a Three-Tier Prescription Copay on Pharmaceutical and Other Medical Utilization." Medical Care 39 (12): 1293-304.

Mullins, C. D., F. B. Palumbo, and M. Saba. 2007. "Formulary Tier Placement for Commonly Prescribed Branded Drugs: Benchmarking and Creation of a Preferred Placement Index." American Journal of Managed Care 13 (2): 377-84.

Nair, K. V., P. Wolfe, R. J. Valuck, M. M. McCollum, J. M. Ganther, and S. J. Lewis. 2003. "Effects of a 3-Tier Prescription Benefit Design on the Prescription Purchasing Behavior of Individuals with Chronic Disease.” Journal of Managed Care Pharmacy 9 (2): 123-33.

National Association of Chain Drug Stores (NACDS). 2008. "Facts and Resources" [accessed on July 1, 2008]. Available at http://www.nacds.org/wmspage.cfm? parm $1=507$ 
Newhouse, J. P. 2006. "Reconsidering the Moral Hazard-Risk Avoidance Tradeoff." Journal of Health Economics 25: 1005-14.

Pesaran, M. H. 2004. General Diagnostic Tests for Cross Section Dependence in Panels. Cambridge Working Papers in Economics, No. 0435. University of Cambridge. Phelps, C. E. 2003. Health Economics. 3d Edition. Boston: Addison-Wesley.

Ramsey, J. B. 1969. "Tests for Specification Errors in Classical Linear Least-Squares Regression Analysis.” Journal of the Royal Statistical Society B (31): 350-71.

Rector, T. S., M. D. Finch, P. M. Dnazon, M. V. Pauly, and B. S. Manda. 2003. "Effect of Tiered Prescription Copayments on the Use of Preferred Brand Medications." Medical Care 41: 398-406.

Shrank, W. H., H. N. Young, S. L. Ettner, P. Glassman, S. M. Asch, and R. L. Kravitz. 2005. "Do the Incentives in 3-Tier Pharmaceutical Benefit Plans Operate as Intended? Results from a Physician Leadership Survey." American Journal of Managed Care 11 (1): 16-22.

StataCorp. 2008. Stata Statistical Software: Release MP 10.1. College Station, TX: StataCorp LP.

Wooldridge, J. M. 2002. Econometric Analysis of Cross Section and Panel Data. Cambridge, MA: MIT Press.

Wu, D. 1973. "Alternative Tests of Independence between Stochastic Regressors and Disturbances." Econometrica 41: 733-50.

\section{SUPPORTING INFORMATION}

Additional supporting information may be found in the online version of this article:

Appendix SA1: Author Matrix.

Table S1: Prescription Drug Utilization over Time $(N=1,074)$.

Table S2: Linear Fixed Effects Models of Generic and Brand Prescription Drug Utilization $(N=1,074)$.

Table S3: Linear Fixed Effects Models of Retail and Mail Prescription Drug Utilization $(N=1,074)$.

Please note: Wiley-Blackwell is not responsible for the content or functionality of any supporting materials supplied by the authors. Any queries (other than missing material) should be directed to the corresponding author for the article. 